\title{
Inhibition of cell proliferation, migration and invasion by DNAzyme targeting MMP-9 in A549 cells
}

\author{
LIFANG YANG ${ }^{1}$, WEIZHONG ZENG ${ }^{2}, \mathrm{DAN} \mathrm{LI}^{3}$ and RUI ZHOU ${ }^{2}$ \\ ${ }^{1}$ Cancer Research Institute, Xiangya School of Medicine, Central South University, Changsha, Hunan 410078; \\ ${ }^{2}$ Respiratory Medicine, Xiangya Second Hospital, Central South University, Changsha, Hunan 410011; \\ ${ }^{3}$ Institute of Life Science and Biotechnology, Hunan University, Changsha, Hunan 410082, P.R. China
}

Received March 4, 2009; Accepted April 20, 2009

DOI: $10.3892 /$ or_00000414

\begin{abstract}
Matrix metalloproteinases (MMPs) have been regarded as major critical molecules assisting tumor cells during angiogenesis and metastasis. Enhanced expression of matrix metalloproteinase-9 (MMP-9) is associated with human non-small cell lung cancer (NSCLC) invasion and metastasis. DNAzyme is a single-stranded DNA catalyst that can be engineered to bind to its complementary sequence in the target gene and cleave the mRNA. In this study, DNAzyme targeting MMP-9 was designed and synthesized. We found it strongly inhibited MMP-9 mRNA and protein expression in the NSCLC cell line A549. Inhibition of cell proliferation, adhesion, migration and invasion was also demonstrated. Thus, DNAzyme targeting MMP-9 may be a promising antiinvasion and anti-metastasis strategy for cancer gene therapy in NSCLC.
\end{abstract}

\section{Introduction}

Lung cancer is the most common cause of cancer-related death in the world. Non-small cell lung cancer (NSCLC) constitutes about $80 \%$ of all lung cancers. The primary reason for the difficulty in treating NSCLC is the development of metastasis (1). Matrix metalloproteinases (MMPs) are a family of structurally related zymogens capable of degrading the extracellular matrix, including the basement membrane. They are considered to be critically involved in the tumor invasion and metastasis of various cancers $(2,3)$. Among the many MMPs that have been identified, MMP-9 is thought to be key enzyme because it can degrade type IV collagen, the main component of epithelial-mesenchymal transition (EMT). Increased expression of MMP-9 was shown to correlate with an invasive phenotype of cancer cells $(4,5)$. MMP-9 was found

Correspondence to: Professor Rui Zhou, Respiratory Medicine, Xiangya Second Hospital, Central South University, Changsha, Hunan 410011, P.R. China

E-mail: zhourui2355@sina.com

Key words: MMP-9, DNAzyme, proliferation, migration, invasion, non-small cell lung cancer to be significantly associated with survival in NSCLC patients and giving an inverse prognostic effect (6-9), thus suggesting MMP-9 as an interesting target for adjuvant anticancer therapy in operable NSCLC using specific inhibitors of MMP-9.

DNAzyme is a DNA residue-based molecule capable of specific cleavage of complementary mRNA. This catalyst has emerged as a potential new class of nucleic acid-based drug because of its relative ease and low cost of synthesis, high stability, and flexible rational design features $(10,11)$. These agents have been used in a number of applications in vivo to inhibit the expression of their target genes. Their capacity to block the development of diverse stages of pathologies in animal models suggested a potential use for DNAzyme as a therapeutic tool (12-14). The purpose of this study was to evaluate the effect of DNAzyme targeting MMP-9 on cell proliferation, adhesion, migration and invasion in human NSCLC A549 cells.

\section{Materials and methods}

Cell culture and transfection. A549 is a NSCLC cell line (ATCC CCL-185). Cells were cultured in RPMI-1640 (Gibco-BRL), supplemented with 10\% FBS (Invitrogen), $10 \mu \mathrm{g} / \mathrm{ml}$ streptomycin and $10 \mathrm{IU} / \mathrm{ml}$ penicillin, incubated in a humidified atmosphere of $5 \% \mathrm{CO}_{2}$ at $37^{\circ} \mathrm{C}$.

One day before transfection, cells were plated in 6wells of growth medium without antibiotics so that cells would be $30-50 \%$ confluent at the time of transfection. The transfection was performed with the manufacturer's protocol for oligofectamine reagent (Invitrogen). Briefly, $4 \mu 1$ of oligofectamine reagent was mixed with $17 \mu 1$ of RPMI-1640, then incubated with a mixture of $4 \mu \mathrm{l}$ DNAzyme $(500 \mu \mathrm{M}$, the final concentration is $2 \mu \mathrm{M}$ (15) and $175 \mu 1$ of RPMI-1640 for an additional $20 \mathrm{~min}$ at room temperature. After $800 \mu \mathrm{l}$ RPMI-1640 was added, $1000 \mu 1$ of DNAzyme and oligofectamine complexes was applied to each well, then incubating for $4 \mathrm{~h}$. Then $500 \mu \mathrm{l}$ of growth medium containing 3-fold the normal concentration of serum was added without removing the transfection mixture. Cells were usually assayed $24 \mathrm{~h}$ after transfection.

DNAzyme synthesis. Based on the analysis of sequences, thermodynamics and site distribution within the MMP-9 
gene, the DNAzyme targeting MMP-9 mRNA was designed and synthesized $(10,15)$, purified by high-pressure liquid chromatography. The Control oligo (antisense equivalent of DNAzyme, mutated the catalytic domain) served as a control. To increase the resistance against nuclease degradation, the phosphorothioate modifications were incorporated in the first and last two phosphodiester linkages. The sequences were the following: DNAzyme: 5'-aggegcccaGGCTAGCTACA ACGActccgcggc-3'; Control oligo: 5'-aggcgeccaGGGATCG TACAACGActccgcggc-3'.

Quantitative real-time RT-PCR. For quantitative mRNA expression analysis, a SYBR real-time RT-PCR protocol was applied using an ABI5700 (Applied Biosystems) instrument. Quantification of the copy number of MMP-9, was performed by serial dilutions of cDNA fragments $\left(10^{3}\right.$ up to $10^{6} \mathrm{cDNA}$ copies), which form the T-vector pGEM (Promega) with MMP-9. Total RNA was isolated with TRIzol Reagent (Invitrogen) and reverse transcriptase reaction was performed using $2 \mu \mathrm{g}$ total RNA by Superscript II enzyme (Gibco-BRL). The primers of MMP-9 were the following: 5'-tcctcg ccctgaacctg-3' (forward) and 5'-cttcccatccttgaacaaatac-3' (reverse). Reactions were performed in a $20 \mu \mathrm{l}$ volume with $0.5 \mu \mathrm{M}$ primers, $5 \mathrm{mM} \mathrm{MgCl}_{2}$, Nucleotides, Taq DNA polymerase, and buffer were included in the DNA Master SYBR-Green I mix (Applied Biosystems). Cycling conditions were: $95^{\circ} \mathrm{C} 10 \mathrm{~min}$, followed by 30 cycles at $95^{\circ} \mathrm{C}$ for $15 \mathrm{sec}$, $58^{\circ} \mathrm{C}$ for $30 \mathrm{sec}$, and $72^{\circ} \mathrm{C}$ for $30 \mathrm{sec}$. Specificity of amplification products was confirmed by melting curve analysis.

Western blot analysis. After transfection for $24 \mathrm{~h}$, cells were lysed in the lysis buffer $(10 \mathrm{mM}$ Tris- $\mathrm{HCl}, \mathrm{pH} 8.0,1 \mathrm{mM}$ EDTA, 2\% SDS, $5 \mathrm{mM}$ DTT, $10 \mathrm{mM}$ PMSF, proteinase inhibitors mix), and then the protein quantified was applied by the BCA Assay Reagent (Pierce Chemical). Total protein was resolved on $10 \%$ polyacrylamide SDS gel and transferred onto a nitrocellulose membrane by electroblotting. The membrane was incubated in blocking buffer (TBS containing $5 \%$ skim-milk and $1 \%$ Tween-20) for $2 \mathrm{~h}$, followed by incubation with the primary antibody. Blots were then incubated with peroxidase-conjugated secondary antibodies. Protein expressions were determined using a super signal chemiluminescence system (ECL, Pierce), followed by exposure to autoradiographic film. The study employed antibodies against MMP-9 (sc-21733, Santa Cruz Biotechnology), and Actin (sc-8432, Santa Cruz Biotechnology). Relative protein levels were quantified by the use of ImageJ software (NIH) on scanned film.

Cell proliferation assay. A549 cells transfected with mock, Control oligo or DNAzyme in 96-well plates were incubated for $24-48 \mathrm{~h}$. After incubation, MTT dye $(0.5 \mathrm{mg} / \mathrm{ml})$ was added to each well for further $4 \mathrm{~h}$ incubation. The reaction was stopped by the addition of DMSO, and the absorption was determined at $570 \mathrm{~nm}$ on a multiple-well plate reader (BioTek). The survival rate of cells was expressed as $A / B 100 \%$, where $A$ was the absorbance value from the experimental cells and $B$ was that from the control cells, which were not treated.
In vitro cell adhesion assay. Twenty-four-well plates were incubated with $150 \mu \mathrm{l} /$ well of fibronectin (Gibco) $(50 \mu \mathrm{g} / \mathrm{ml})$ for $45 \mathrm{~min}$ and blocked with $1 \%$ bovine serum album. A549 cells after transfected for $24 \mathrm{~h}$ with mock, Control oligo or DNAzyme were harvested for the cell adhesion assay. Cell mixture $(100 \mu \mathrm{l})\left(10^{5}\right.$ cells $\left./ \mathrm{ml}\right)$ was added to each well and allowed to attach for 2 and $4 \mathrm{~h}$ at $37^{\circ} \mathrm{C}$. After three times of washing with PBS to remove non-adherent cells, the number of adherent cells was counted. Each assay was performed in triplicate in at least two independent experiments.

Wound-healing/cell migration assay. The assay was performed on 6-well plates coated with the extracellular matrix protein, fibronectin (Gibco). A549 cells after transfection were grown to confluent monolayers in a 6-well plate for $24 \mathrm{~h}$, then the monolayers were disrupted by scraping them with a sterile P200 micropipette tip, and cultured for $24 \mathrm{~h}$, the migration ability of the cells was evaluated by measuring the width of the wounds (measured at x400 magnification). Each assay was performed in triplicate in at least two independent experiments.

Cell invasion assays. The cell invasion assay was conducted using BD Biocoat Matrigel 24-well invasion chambers with filters coated with Matrigel on the upper surface (BD Biosciences, Bedford, MA) with $8.0 \mu \mathrm{m}$ pores. A549 cells were transfected with mock, Control oligo or DNAzyme. After $24 \mathrm{~h}$, the cells were trypsinized, resuspended in serumfree medium, seeded $1 \times 10^{5}$ cells in $0.2 \mathrm{ml}$ medium to the upper chamber, and $0.5 \mathrm{ml} 10 \%$ FBS medium was added to the lower chamber, after incubation at $37^{\circ} \mathrm{C}$ with $5 \% \mathrm{CO}_{2}$ for $24 \mathrm{~h}$, the cells were stained with $0.1 \%$ Crystal violet solution, and the cells and Matrigel on the top surface of the filter were carefully removed with a cotton swab. The invasive cells attached to the bottom surface of the filter were quantified under a light microscope (x200). The data are presented as the average number of cells from randomly chosen fields. Each treatment condition was assayed using triplicate filters and filters were counted in five areas.

Statistical analysis. Statistical analyses were carried out by Student's t-test (SPSS.V11.0). The p-values $\leq 0.05$ were considered significant.

\section{Results}

DNAzyme inhibits MMP-9 mRNA expression in A549 cells. As shown in Fig. 1, the DNAzyme had obvious inhibition effect on MMP-9 mRNA levels in the A549 cells, whereas the Control oligo had no effect $(p<0.01)$. The copies of MMP-9 of the mock, Control oligo and DNAzyme was $3.94 \pm 0.75 \times 10^{5} / \mu \mathrm{g}$ RNA, $3.86 \pm 0.69 \times 10^{5} / \mu \mathrm{g}$ RNA, $6.25 \pm$ $1.06 \times 10^{2} / \mu \mathrm{g}$ RNA (means $\pm \mathrm{SE}$ ), respectively. These results indicated that the targeting MMP-9 DNAzyme inhibited the MMP-9 mRNA expression in A549 cells.

Effect of DNAzyme blockade on MMP-9 protein expression. DNAzyme was transfected into A549 cells and assayed for its effect on the MMP-9 expression at the protein level using Western blotting. As shown in Fig. 2, the expression of 

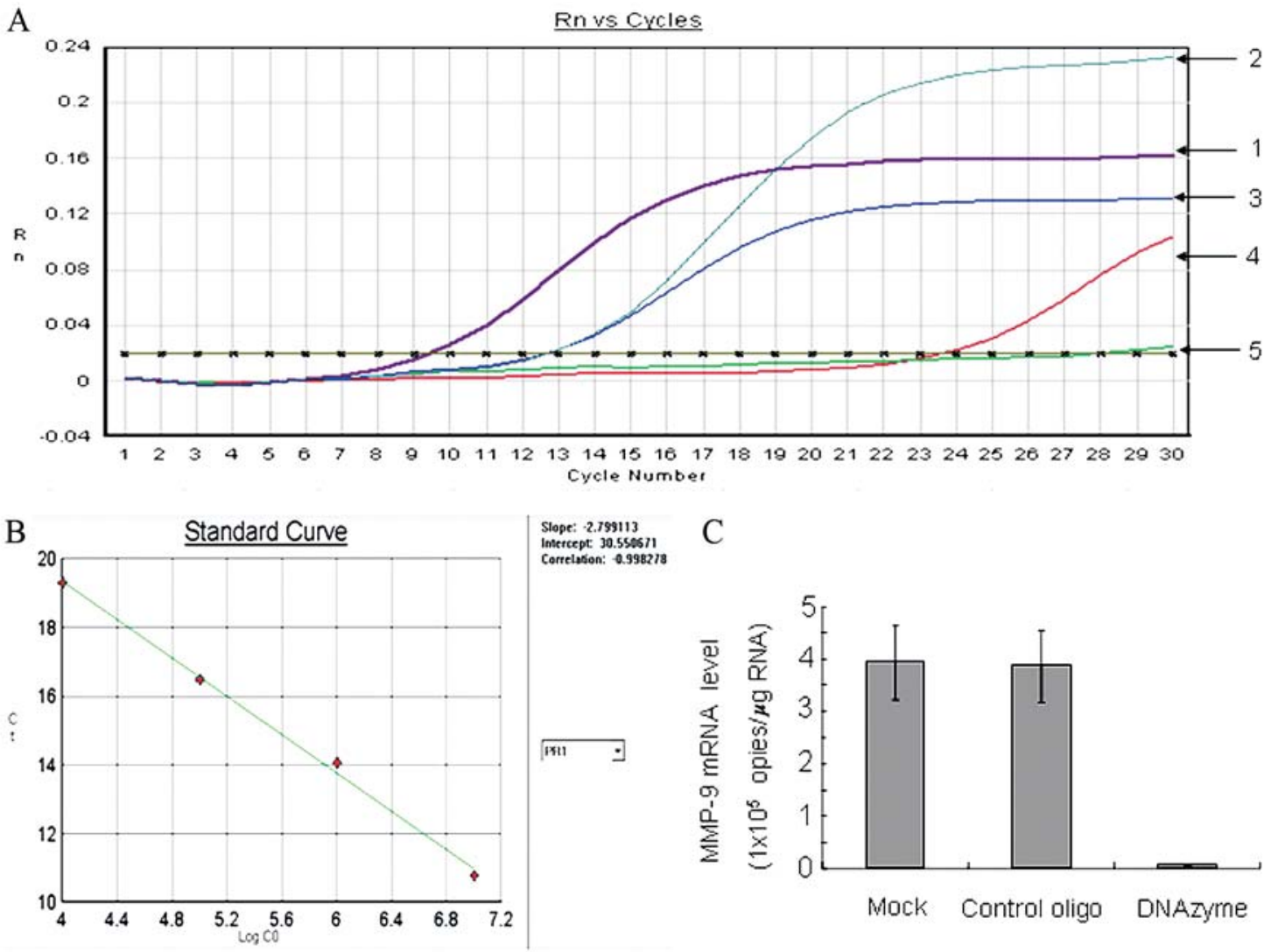

Figure 1. The MMP-9 mRNA was analyzed by SYBR real-time RT-PCR. (A) The detection curves of real-time RT-PCR of MMP-9 mRNA. 1, positive control; 2, mock; 3, control oligo; 4, DNAzyme; 5, negative control. (B) The standard curve for MMP-9 obtained by SYBR-Green PCR using plasmid DNA as template. (C) $\mathrm{p}<0.01$ (relative to those in the control group). Columns, means; bars, $\pm \mathrm{SE}$. The experiment was repeated three times.

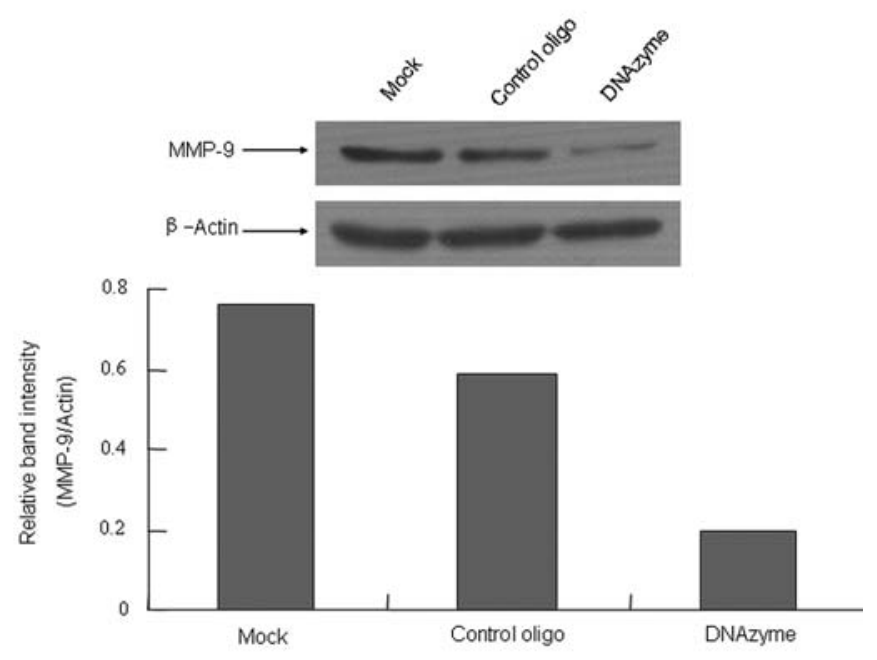

Figure 2. Blockade of MMP-9 protein expression in A549 cells by DNAzyme. Expression level of each protein was estimated by densitometry and presented as a ratio to the loading control Actin. $\mathrm{p}<0.05$ (relative to those in the control group).

MMP-9 was strongly decreased in A549 cells transfected with DNAzyme compared with Control oligo and mock $(\mathrm{p}<0.05)$, the relative band intensity units of DNAzyme, Control oligo and mock were $0.2010 .759,0.588$, respectively.

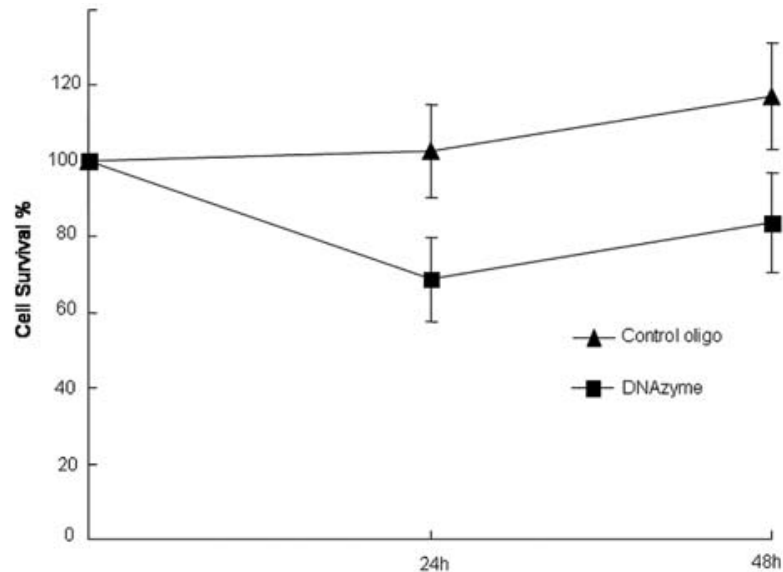

Figure 3. The A549 cell proliferation assessed by MTT assay. $\mathrm{n}=6, \mathrm{p}<0.05$ (relative to those in the control group). Means; bars, $\pm \mathrm{SE}$.

Inhibition of A549 cell growth by targeting MMP-9 DNAzyme. The A549 cell proliferation was assessed by MTT assay. A549 cell proliferation was suppressed by treatment with DNAzyme compared with the treatment of Control oligo $(\mathrm{n}=6, \mathrm{p}<0.05)$ (Fig. 3). These findings demonstrated that the growth of A549 cells could be inhibited by DNAzyme targeting MMP-9.

Targeting MMP-9 DNAzyme inhibit the adhesion of A549 cells. The attachment rate after 2 h of A549 cell transfection 


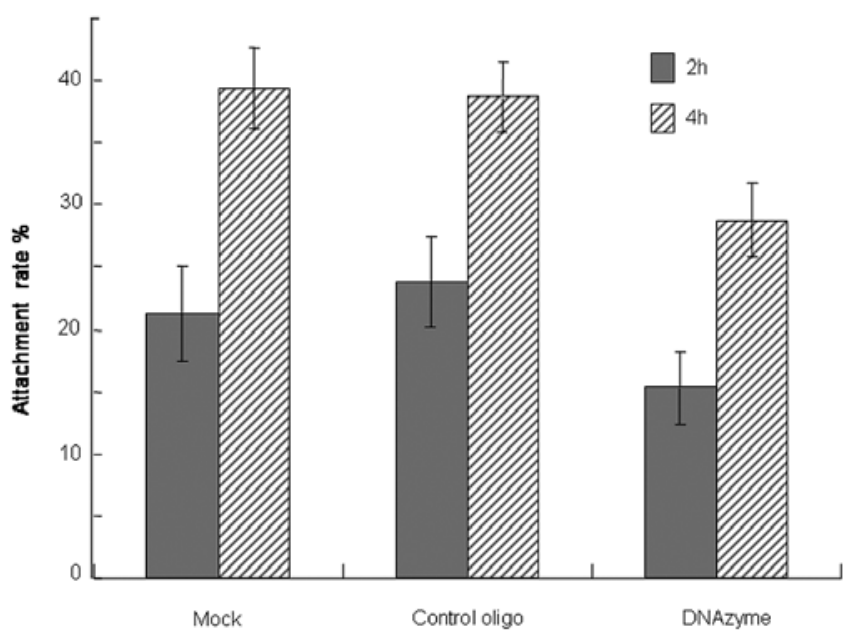

Figure 4. Inhibition of A549 cell adhesion by targeting MMP-9 DNAzyme. $\mathrm{p}<0.05$ (relative to those in the control group). Columns, means; bars, $\pm \mathrm{SE}$ Each sample was assayed in triplicate, and at least two independent experiments.

with DNAzyme to fibronectin was $15.34 \pm 2.86$ (means \pm SE, $\%)$. It was lower than the cells treated with Control oligo and mock $(\mathrm{p}<0.05)$ (Fig. 4). The attachment rates were $21.28 \pm 3.81,23.80 \pm 3.65$, respectively. The result was similar to the attachment rate after $4 \mathrm{~h}$, which was $28.70 \pm 3.09$, $39.32 \pm 3.25,38.64 \pm 2.98$, respectively.
Inhibition of A549 cell migration by targeting the MMP-9 DNAzyme. To provide further support for the effect of the targeting of MMP-9 by DNAzyme, in vitro scratch wound healing assay was performed. The results are shown in Fig. 5. The migration rate of treatment with DNAzyme was $3.34 \pm 0.52$ (means $\pm \mathrm{SE}, \mu \mathrm{m} / \mathrm{h}$ ), being significantly inhibited compared to cells treated with Control oligo and mock $(\mathrm{p}<0.05)$, which was 5.32 $\pm 0.86,5.21 \pm 0.92$, respectively. Therefore, the DNAzyme targeting of MMP-9 inhibited the migration of A549 cells.

Targeting of MMP-9 DNAzyme decreases A549 cell invasiveness. The invasive potential of the A549 cells after transfection with targeting MMP-9 DNAzyme was determined using the Matrigel invasion assay. Fig. 6C shows decreased staining of the invaded cells through the Matrigel with targeting MMP-9 DNAzyme transfected compared with the Control oligo and mock controls (Fig. 6A and B). Quantitative analysis indicated that the targeting of MMP-9 by DNAzyme decreased $50 \%$ the invasiveness of the A549 cells compared with controls $(\mathrm{p}<0.05)$ (Fig. 6D). These data suggest that the targeting of MMP-9 by DNAzyme remarkably inhibited the invasive capacity of the A549 lung cancer cells.

\section{Discussion}

In recent years, much attention has been focused on antimetastatic agents constructed by genetic engineering techniques for the therapy of malignant tumor cells. Down-

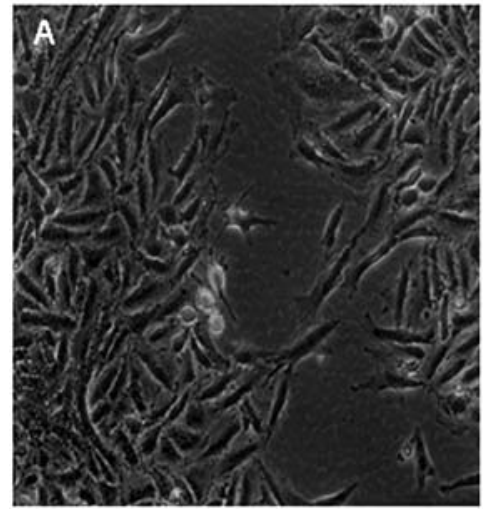

Mock

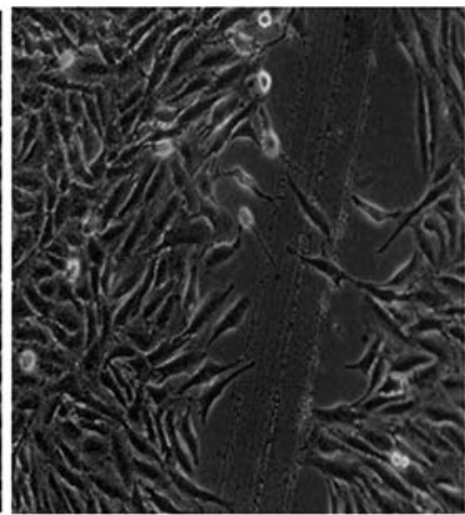

Control oligo

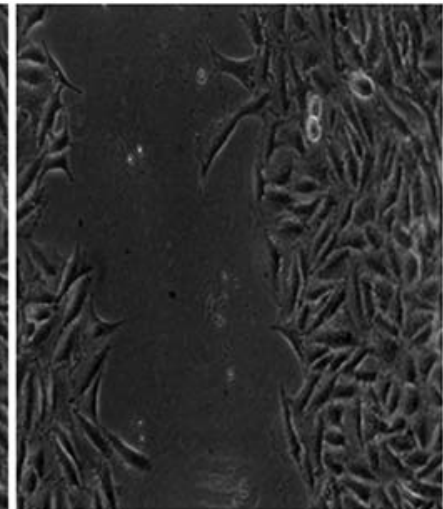

DNAzyme

B

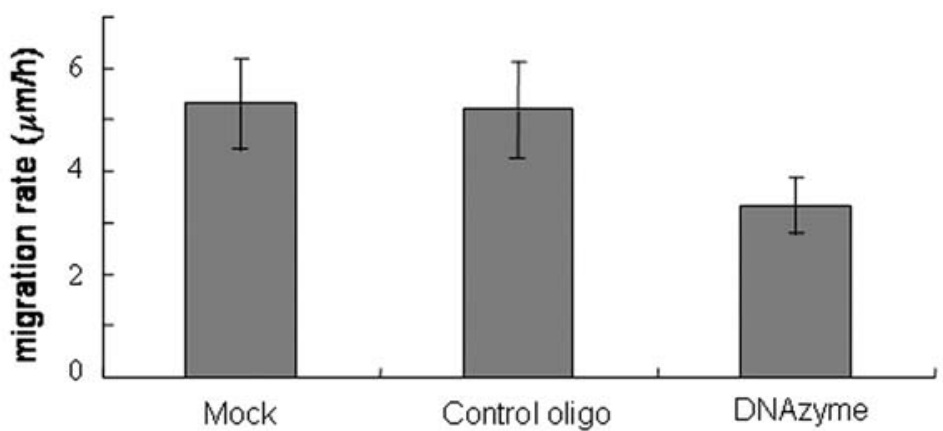

Figure 5. DNAzyme targeting MMP-9 inhibits A549 cell migration in vitro. $\mathrm{p}<0.05$ (relative to those in the control group). Columns, means; bars, \pm SE. Measured at $\mathrm{x} 400$ magnification. Panel A shows the results from single experiments, in which each sample was assayed in triplicate, and are representative of at least two independent experiments. 

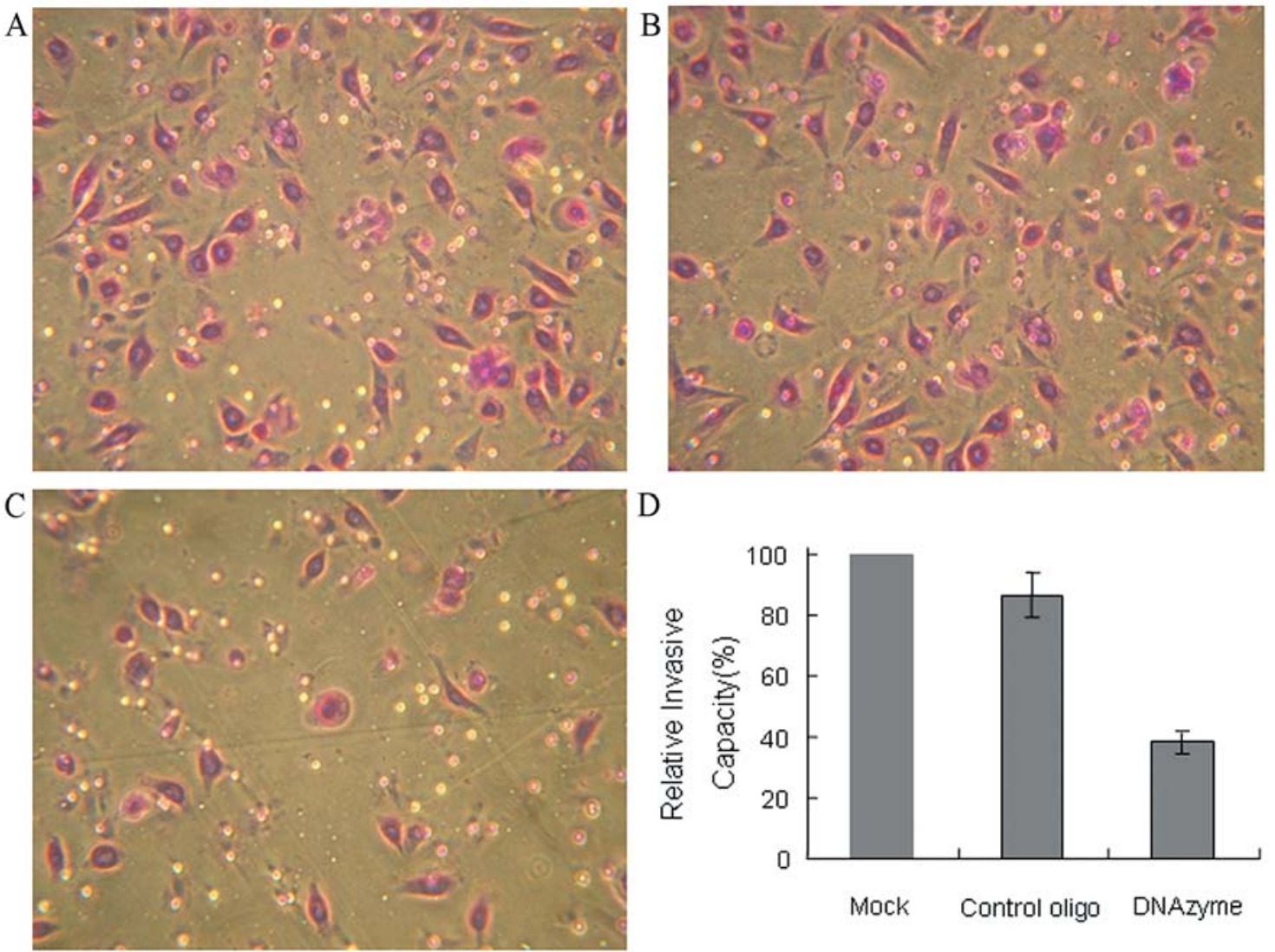

$\mathrm{D}$

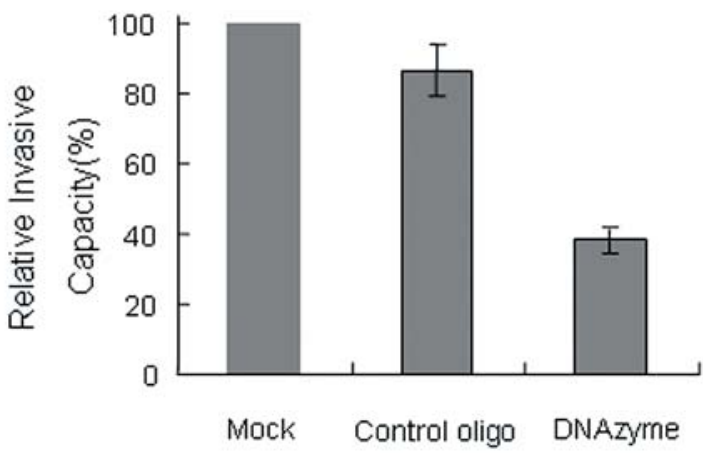

Figure 6. Targeting MMP-9 DNAzyme inhibits lung cancer cell invasiveness through Matrigel. (A-C) Representative images of the cells on the lower side of a membrane $24 \mathrm{~h}$ after plating for the invasion assay. Measured at x200 magnification. (D) Invasive activity was determined as the percent invasion through Matrigel matrix and membrane relative to controls. Columns, mean of at least two independent experiments; bars, \pm SE.

regulation of MMP-9 by RNAi or antisense DNA constructs has been used to diminish production of MMP-9 in tumor cells (16-20). Target silencing of MMP-9 by RNAi in human Ewing's sarcoma indicated that MMP-9 constitutes a trigger for the switch between the adhesive and migratory states of tumor cells by regulating E-cadherin-mediated cell adhesion, extracellular matrix (ECM)-mediated cell spreading and paxillin signaling (16). Downregulation of MMP-9 in a prostate carcinoma xenograft model with specific antisense construct inhibited tumor growth (17). Further study implicated an anti-apoptotic role of MMP-9 shown to render tumor cells resistance to apoptosis (18). The cysteine protease cathepsin B and the MMP-9 played important roles in tumor progression. The migration and invasion of meningioma cells were decreased after treatment with siRNA constructs for cathepsin B and MMP-9. Furthermore, the abrogation of cathepsin B and MMP-9 expression decreased the activation of major proteins involved in MAP kinase and PI3 kinase pathways (19). In addition, MMP-9 were interrelated with the uPA/uPAR system in metastasis, the functional role of MMP-9/uPAR was highlighted in experiments of downregulation of MMP-9 and UPAR in lung carcinoma cells with antisense constructs. The downregulation of MMP-9 efficiently inhibited tumor cell invasion, angiogenesis and tumor growth, and even lung metastasis (20). Taken together, these studies implicated multiple functional roles of MMP-9 in the development of secondary metastasis, and strongly indicated of that MMP-9 could modify the microenvironment of the tumor either leading to enhanced or diminished tumor cell dissemination and metastasis formation.

Recent studies have shown the potential of DNAzyme can serve as drugs both in cell-based assays and preclinical models of cancer. The DNAzymes could offer the advantages of catalytic activity with inherent stability and low cost of synthesis $(21,22)$. However, most important in gene therapy of DNAzyme is how to improve their stability in the body. In order to enhance the stability of DNAzyme, many scholars have tried to modify the DNAzyme, including phosphorothioate, $3^{\prime}$ terminl reverse, N3'-P5' phosphorus amide modified, 2'-O-methylation, LNAzyme modified by LNA (Locked nucleic acid), and so on (22). It is anticipated that with the development of smart delivery systems for DNAzymes, better pharmacokinetics and pharmacodynamics will be possible (10).

In this study, we explored the potential of using DNAzyme as an anti-metastasis strategy for cancer gene therapy in NSCLC by targeting the MMP-9 gene. This study indicated that the targeting of MMP-9 by DNAzyme downregulated the MMP-9 expression at the mRNA and protein level, and inhibited the cell proliferation, adhesion, migration and invasion in the NSCLC cell line A549. In conclusion, DNAzyme targeting of the MMP-9 may serve as useful antimetastasis agent in NSCLC. 


\section{Acknowledgments}

This work was supported by grants from the China National Natural Sciences Foundation (30873010 and 30872763) and the Natural Science Foundation of Hunan Province, China (03JJY4036).

\section{References}

1. Shottenfeld D: Epidemiology of lung cancer. In: Lung Cancer. Pass HI, Mitchell JB, Johnson DH, Turrisi AT and Minna JD (eds). Lippincott Williams \& Wilkins, Philadelphia, pp367-88, 2003

2. Deryugina EI and Quigley JP: Matrix metalloproteinases and tumor metastasis. Cancer Metastasis Rev 25: 9-34, 2006.

3. MacKay AR, Corbitt RH, Hartzler JL and Thorgeirsson UP: Basement membrane type IV collagen degradation: evidence for the involvement of a proteolytic cascade independent of metalloproteinases. Cancer Res 50: 5997-6001, 1990.

4. Stamenkovic I: Extracellular matrix remodelling: the role of matrix metalloproteinases. J Pathol 200: 448-464, 2003

5. Nakamura T, Kuwai T, Kim JS, Fan D, Kim SJ and Fidler IJ: Stromal metalloproteinase-9 is essential to angiogenesis and progressive growth of orthotopic human pancreatic cancer in parabiont nude mice. Neoplasia 9: 979-986, 2007.

6. Bugdayci G, Kaplan T, Sezer S, Turhan T, Koca Y, Kocer B and Yildirim E: Matrix metalloproteinase-9 in broncho-alveolar lavage fluid of patients with non-small cell lung cancer. Exp Oncol 28: 169-177, 2006

7. Leinonen T, Pirinen R, Bohm J, Johansson R, Ropponen K and Kosma VM: Expression of matrix metalloproteinases 7 and 9 in non-small cell lung cancer. Relation to clinicopathological factors, beta-catenin and prognosis. Lung Cancer 51: 313-321, 2006

8. Sienel W, Hellers J, Morresi-Hauf A, Lichtinghagen R, Mutschler W, Jochum M, Klein C, Passlick B and Pantel K: Prognostic impact of matrix metalloproteinase-9 in operable non-small cell lung cancer. Int J Cancer 103: 647-651, 2003.

9. Rollin J, Regina S, Vourch P, Iochmann S, Blechet C, Reverdiau P and Gruel Y: Influence of MMP-2 and MMP-9 promoter polymorphisms on gene expression and clinical outcome of non-small cell lung cancer. Lung Cancer 56: 273-280, 2007.

10. Dass CR, Choong PF and Khachigin LM: DNAzyme technology and cancer therapy: cleave and let die. Mol Cancer Ther 7 : 243-251, 2008
11. Isaka Y: DNAzymes as potential therapeutic molecules. Curr Opin Mol Ther 9: 132-136, 2007.

12. Qu Y, Zhang L, Mao M, Zhao F, Huang X, Yang C, Xiong Y and Mu D: Effects of DNAzymes targeting Aurora kinase A on the growth of human prostate cancer. Cancer Gene Ther 15: 517-525, 2008

13. Mitchell A, Dass CR, Sun LQ and Khachigian LM: Inhibition of human breast carcinoma proliferation, migration, chemoinvasion and solid tumour growth by DNAzymes targeting the zinc finger transcription factor EGR-1. Nucleic Acids Res 32: 3065-3069, 2004

14. Zhang G, Dass CR, Sumithran E, Di Girolamo N, Sun LQ and Khachigian LM: Effect of deoxyribozymes targeting c-Jun on solid tumor growth and angiogenesis in rodents. J Natl Cancer Inst 96: 683-696, 2004.

15. Lu ZX, Ma XQ, Yang LF, Wang ZL, Zeng L, Li ZJ, Li XN, Tang M, Yi W, Gong JP, Sun LQ and Cao Y: DNAzymes targeted to EBV-encoded latent membrane protein-1 induce apoptosis and enhance radiosensitivity in nasopharyngeal carcinoma. Cancer Lett 265: 226-238, 2008.

16. Sanceau J, Truchet S and Bauvois B: Matrix metalloproteinase-9 silencing by RNA interference triggers the migratory-adhesive switch in Ewing's sarcoma cells. J Biol Chem 278: 36537-36546, 2003.

17. London CA, Sekhon HS, AroraV, SteinDA, Iversen PL and Devi GR: A novel antisense inhibitor of MMP-9 attenuates angiogenesis, human prostate cancer cell invasion and tumorigenicity. Cancer Gene Ther 10: 823-832, 2003.

18. Meyer E, Vollmer JY, Bovey R and Stamenkovic I: Matrix metalloproteinases 9 and 10 inhibit protein kinase $C$ potentiated, p53-mediated apoptosis. Cancer Res 65: 4261-4272, 2005.

19. Tummalapalli P, Spomar D, Gondi CS, Olivero WC, Gujrati M, Dinh DH and Rao JS: RNAi-mediated abrogation of cathepsin B and MMP-9 gene expression in a malignant meningioma cell line leads to decreased tumor growth, invasion and angiogenesis. Int J Oncol 31: 1039-1050, 2007.

20. Rao JS, Gondi C, Chetty C, Chittivelu S, Joseph PA and Lakka SS: Inhibition of invasion, angiogenesis, tumor growth, and metastasis by adenovirus-mediated transfer of antisense uPARand MMP-9 in non-small cell lung cancer cells. Mol Cancer Ther 4: 1399-1408, 2005

21. Dass CR: Preclinical anticancer activity of DNA-based cleavage molecules. Drug Dev Ind Pharm 32: 1-5, 2006.

22. Dass CR, Saravolac EG, Li Y and Sun LQ: Cellular uptake, distribution, and stability of 10-23 deoxyribozymes. Antisense Nucleic Acid Drug Dev 12: 289-299, 2002. 